\title{
Form follows idea: ideation and CADCAM
}

\author{
L. Barrow \\ Design Research and Informatics Lab (DRIL), School of Architecture, \\ College of Architecture, Art and Design, \\ Mississippi State University, USA
}

\begin{abstract}
In the mid 1990s, we have seen the computer impact the architecture process in the area of 3D modeling and "visualization;" however, this 3D phenomenon, until very recently, has generally been confined to "marketing" presentations in the form of renderings and animations. In architecture, most design studios have remained isolated from the computer, typically using $2 \mathrm{D}$ free-hand drawings on traditional paper based media. Many have claimed the computer is a hindrance to creativity; however, some at the forefront of creativity, with technology, see the computer as not only a making "tool" but also a design "partner" in form ideation and conceptualization.

This paper will analyze the advanced "digital design" process used by the writer's student in a graduate level Digital Design II course. The student entered our "post-professional" graduate program as a means of learning more about design, technology and architecture. This provided an opportunity to do research in the area of digitally driven form concepts. For the inquiry, the student chose to use the "skyscraper" as a means of exploration for digital form generation. The student's concept, the "female-human figure" was only feasible to translate into architectonic form using digital design techniques via 3D free-form "virtual" modeling and 3D printing "physical" modeling output. CADCAM tools proved to be empowering for the student's exploration, learning and design creativity.

With the recent emergence of both more user-friendly hardware and software, we are seeing a paradigm shift in design "ideation." This is attributed to the evolving human-computer-interface (HCI) that now allows a fluidic means of creative design ideation, digital representation and physical making. Computing technology is now infusing early conceptual design ideation and allowing designers, and form, to follow their ideas.

Keywords: design, design ideation, digital design, computer-aided-design, computer-aided-manufacturing, CADCAM, representation, visualization, virtual $3 D$ models, physical $3 D$ models.
\end{abstract}




\section{Introduction}

Early architectural computing theorists conceived of "rational" applications of computing in architecture; during this early period of the 1960-1970s, this was quite natural as one-dimensional (1D) binary "text and numbers" were the primary output capability of early computing. This "rational" attitude coincided with "systems thinking" and scientific "numerical computation" which represented the forefront of technology during this early era.

During the 1980s, we saw the emergence of basic computer graphics, this influenced architecture primarily in the area of two-dimensional (2D) representations, and hence the adoption of "digital" drafting techniques. This twenty year old phenomena has remained dominate in mainstream architecture which, in the words of Michael Hammer [1], "paved the cow-paths" by accepting the digital "automation" of traditional design "ideas" and representational strategies.

In this evolving process of architecture, areas of discrete "islands" have maintained autonomy; these areas are primarily noted as 1) conceptual ideation, 2) visualization 3) production 4) construction and 5) operation. The area of "construction (i.e. making) includes a myriad of complex representational "drawings," and recently emerging 3D "representations," in order to actually "construct" a building. It is now well established that a major paradigm shift is occurring based on the ubiquitous immersion of 3D modeling in all phases of the process of architecture (i.e. design-build-operate) [2-4]. This very complex topic, often referred to as Building-Information-Modeling (BIM) is well beyond the scope of this paper. For the sake of brevity, this paper will focus on early conceptual design ideation.

\section{Design thinking}

In architecture, both in practice and pedagogy, most design studios have remained isolated from the computer, typically using 2D free-hand drawings on traditional paper based media. With the recent emergence of both more userfriendly hardware and software, we are seeing a paradigm shift in design "ideas." Where many have claimed the computer is a hindrance to creativity, some at the forefront of technology see the computer not only as a "tool" to make their ideas, but also as a design "partner" in form ideation and conceptualization [2, 5-7].

Heretofore, 3D digital models have generally been used as a "representational" tool for a pre-conceived "idea" that was generated prior to the intellectual or physical engagement of the computer. Often, designers have complained the computer "confines" their ideas and traps their "ideas" inside "the box," (i.e. the flat screen 2D world of the monitor) [8, 9]. However, as we will see, this problem is being overcome via recent hardware and software developments; additionally, we are seeing a "new" generation of computer users emerge who embrace the "holistic" integration of digital thinking in their design process. 


\section{The design problem}

The design problem was established in the context of a graduate level course entitled Digital Design II taught by the writer in spring 2006. The primary focus of the course is the pursuit of digital ideation and making in architecture using emerging technology. This paper will highlight the work of one of the student's who entered our "post-professional" graduate program as a means of learning more about design, technology and architecture. This provided an opportunity to do research in the area of digitally driven form concepts.

Each student in the course is challenged to develop his or her personal "research" and "inquiry" problem for the semester project. For this proposed inquiry, the student chose to use the "skyscraper" as a means of exploration of digital form generation. Each student was required to do research in their topic area of choice, this being done to gain insights from history as well as evolution into the contemporary context. The student was particularly attentive to architectural designers who are currently regarded as leaders in area of technology and "skyscraper" design (see Figure 1).

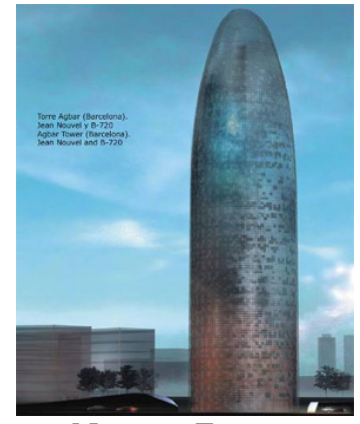

Norman Foster Swiss Re Building

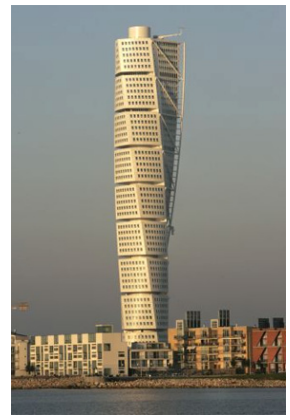

Santiago Calatrava

Tower at Malmo

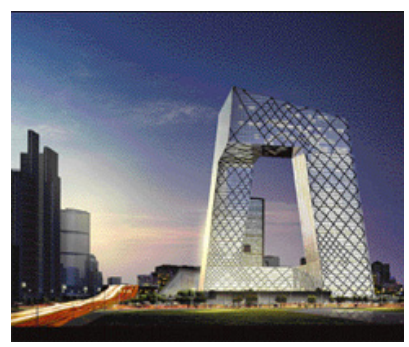

Rem Koolhaus

CCTV Headquarters

Figure 1: $\quad$ Skyscraper - form and technology.

\section{The design process}

The student developed an understanding of the urban context and the issue of world population demographic shifts as we see a shift from agrarian to urban societies. The "skyscraper" was proposed, not unlike earlier "modernist" architects, as a response to transportation and the need for density for amenities offered in the urban context. Thus, the student initiated their representational strategies first in reading, thinking and writing in both numeric and text to generate 1D output. Thereafter, the student began a series of diagrams and sketches that depicted their progressive understanding of the "problem" and the "skyscraper" as an elemental system of core, floor, and skin (see Figure 2). 


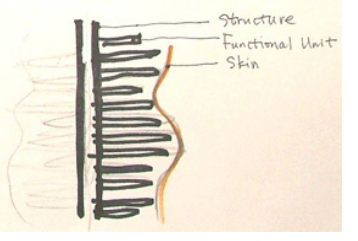

Figure 2: $\quad$ Major elements of a skyscraper.
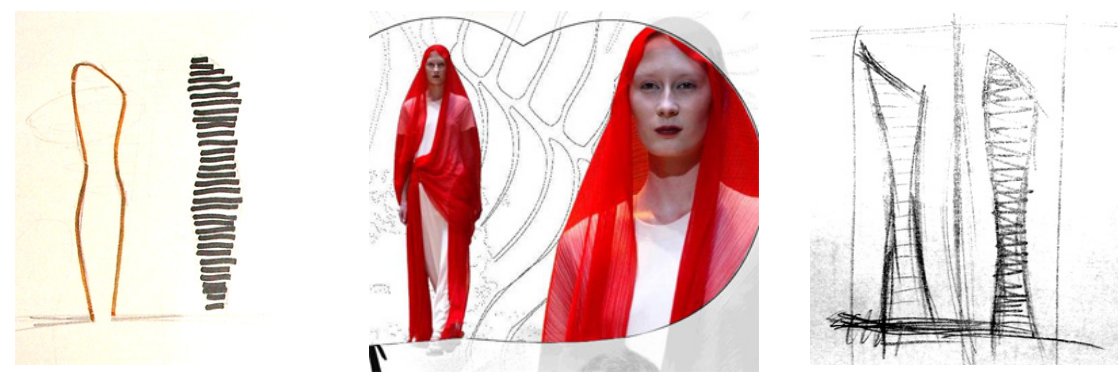

Figure 3: $\quad$ Concept - female human figure.
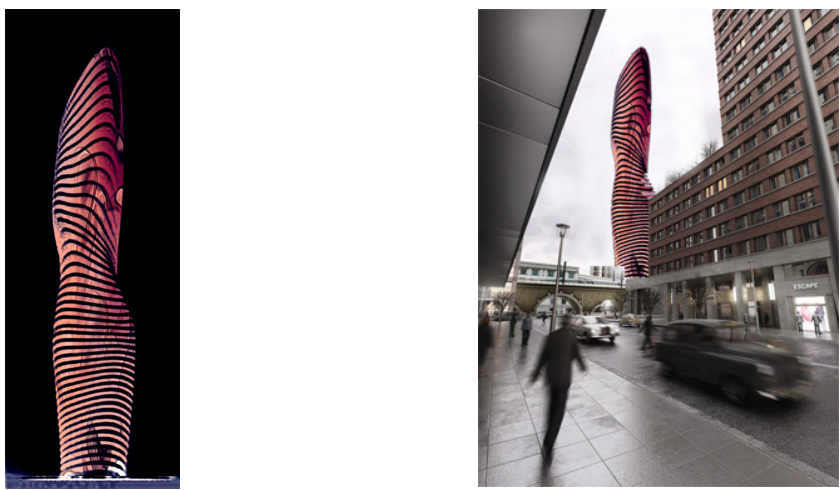

Figure 4: Concept - architectonic development.

Please note that the student used marker or pencil on paper (i.e. traditional media); this particular student has a laptop computer and has tried an external "wacom" tablet; however, the student prefers the direct contact of hand-eye motor interaction of traditional media. About $50 \%$ of our students have PC tablets and are finding significant "comfort" with the digital "free-hand" drawing tools. This area of Human-Computer-Interface (HCI) is very important and will continue to have increasing impact in early ideation representation; however, this is beyond the scope of this paper. Most important to this discussion, we do not dictate any media to the student in the course; we offer a plethora of media, both 
traditional and digital strategies, for both $2 \mathrm{D}$ and $3 \mathrm{D}$ output. We feel this pedagogical position of using the advantages of "all" media to be empowering to the student. Additionally, from a research standpoint, we feel we must be open to all design and media strategies to be unbiased in our scholarly pursuit of digital design methodology. The student's concept evolved into the abstraction of a "female-human figure" (see Figure 3). Pursuant to the 2D paper based media sketches, the student then moved into the digital realm and generated a 2D "freeform" digital reinterpretation of the concept using Photoshop (see Figure 4).

The student then began another series of digital 2D diagrammatic studies using both line and color as visualization aids in AutoCAD. Thereafter, the student began a series of 3D digital models to analyse the form (see Figure 5). An additional series of 3D digital models were generated to study the form proportions in the "virtual" environment using Rhino. Following this analysis, the student then began a series of small "physical" models studies, using the Rhino digital models and a ZCorp 3D printer (see Figure 6).
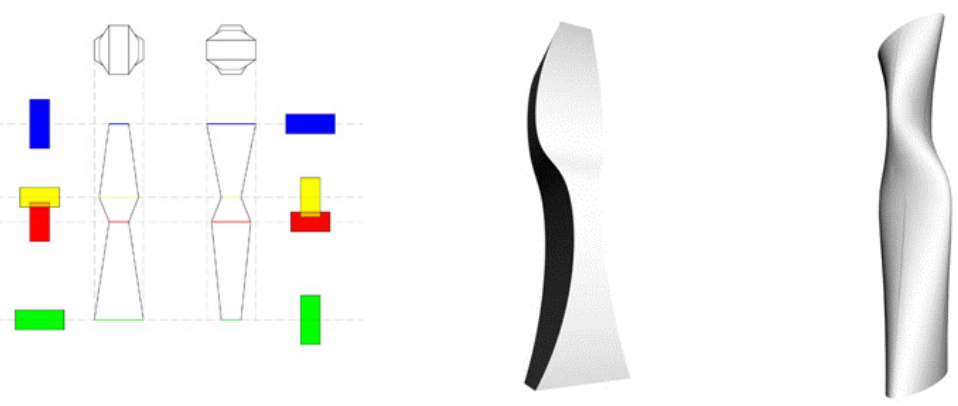

Figure 5: $\quad 2 \mathrm{D}$ and $3 \mathrm{D}$ digital form studies.
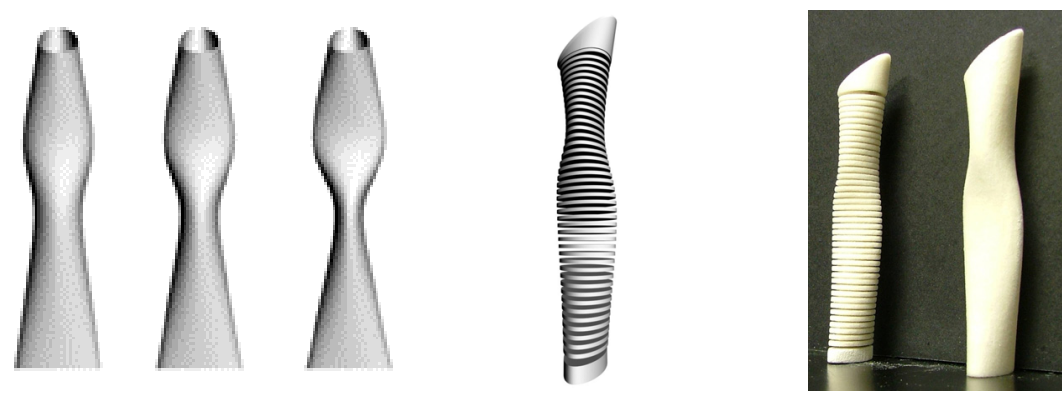

Figure 6: $3 \mathrm{D}$ virtual to $3 \mathrm{D}$ physical model studies.

Following this series of shape and proportion studies, the student then began analysis of structure and skin options. This led the student to a series of digital model studies, with subsequent 3D printed "physical" models to study the scale of a tubular "diamond braced" skin system (see Figures 7 and 8). 


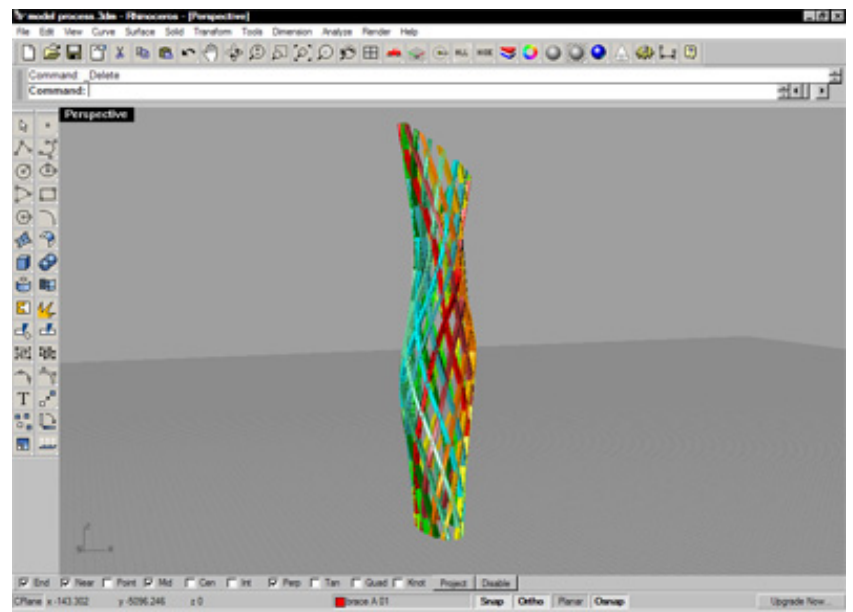

Figure 7: $\quad 3 \mathrm{D}$ virtual model - diamond skin.
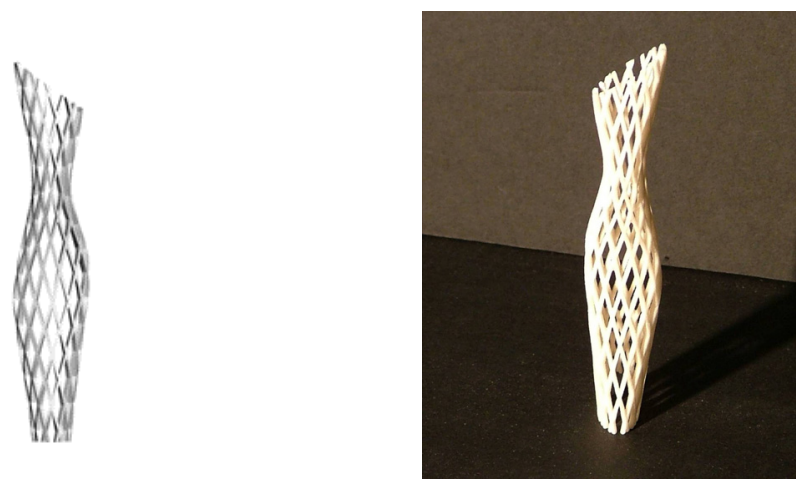

Figure 8: $3 \mathrm{D}$ physical model - diamond skin.
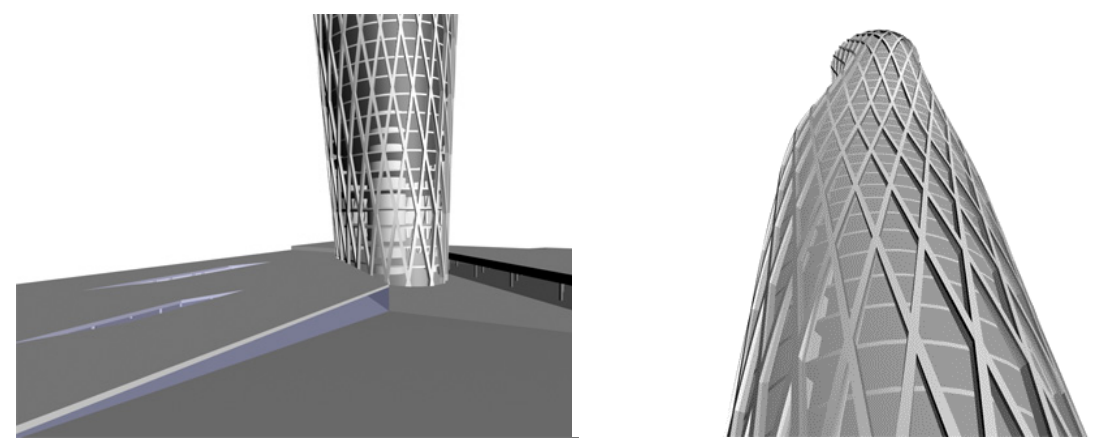

Figure 9: Virtual model output $-2 \mathrm{D}$ images.

The ability to migrate between virtual and physical models was invaluable for the development of the form (see Figures 7-9). 


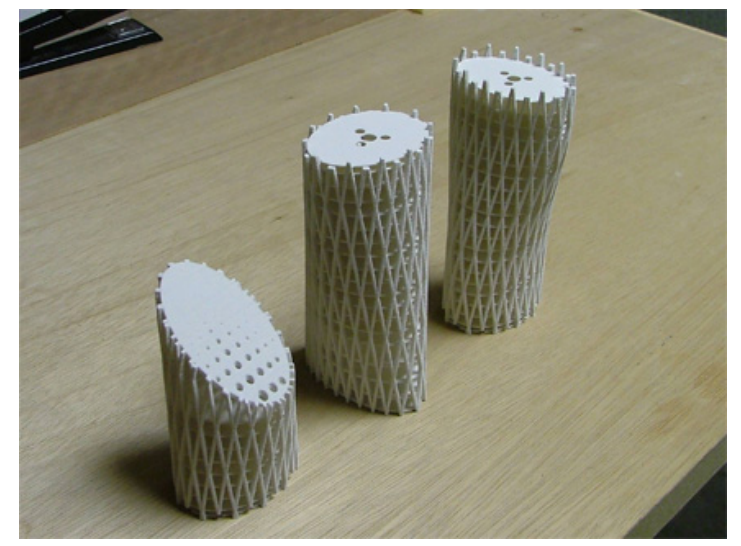

Figure 10: Skyscraper assemblage parts.

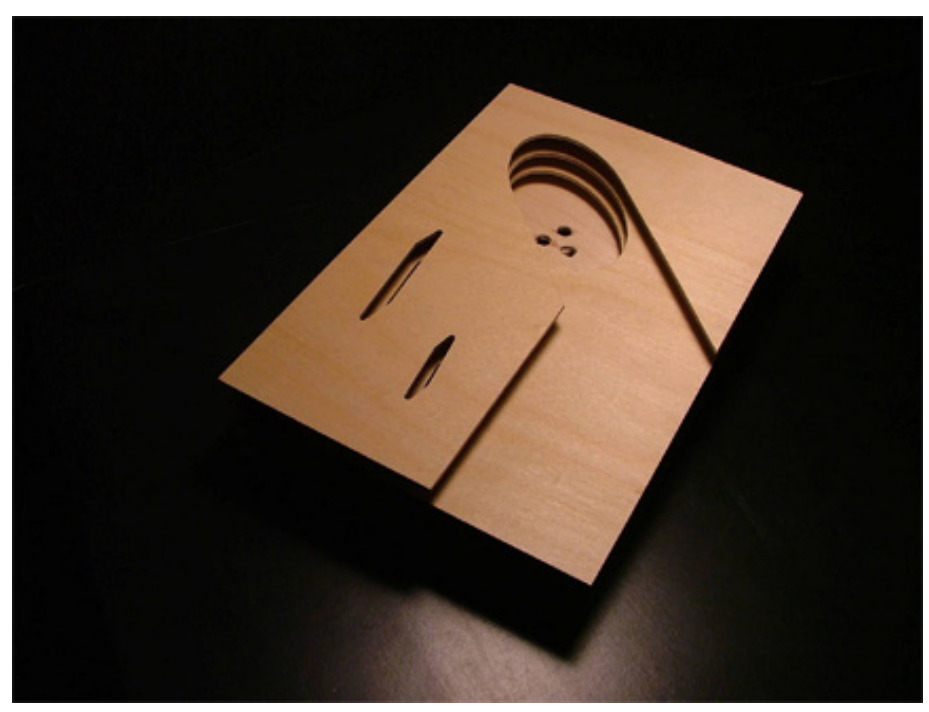

Figure 11: Physical site model $-\mathrm{CNC}$ routed.

The representational physical 3D printed study models varied in scale from 1:2000 to 1:500. The use of CADCAM allowed accelerated learning of representational strategies to the student; the act of "making" with the "machine" allowed iterative small "test" 3D models to be quickly generated for the student to analyze the appropriate amount of detail and information to be included in various scale physical models. Additionally, part of the challenge for the later developed larger 1:500 scale 3D printed models was the size constraints for output of our ZCorp 310 3D printer. Thus, part of the learning experience for the student was the challenge of how to CADCAM the elements of the skyscraper as 
a "kit-of-parts." This required "parts and assemblages" thinking by the student, which we teach and feel to be relevant in the emerging paradigm shift in the "making" and "manufacturing" of architecture [10] (see Figure 10).
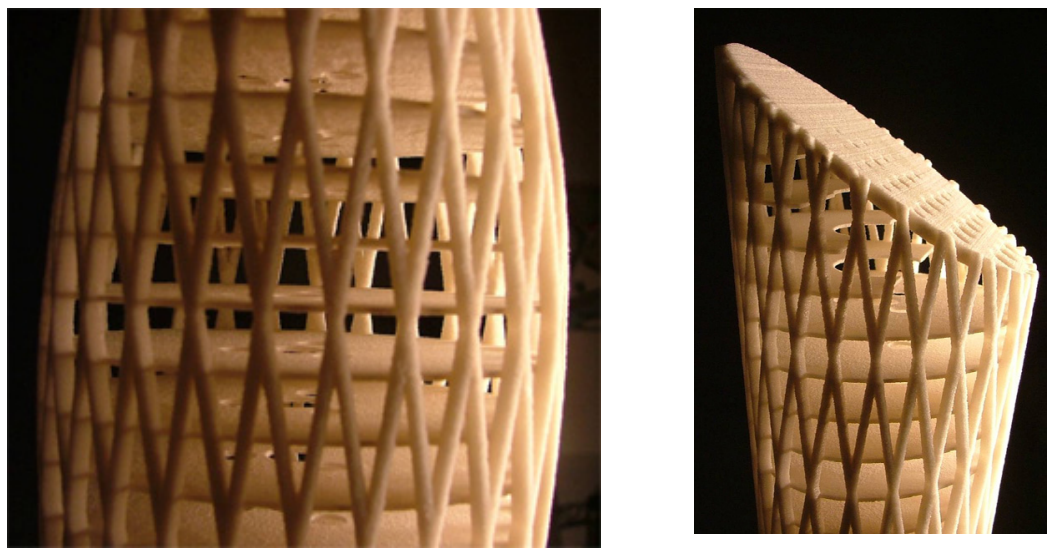

Figure 12: $\quad$ Physical model output - 3D printed.

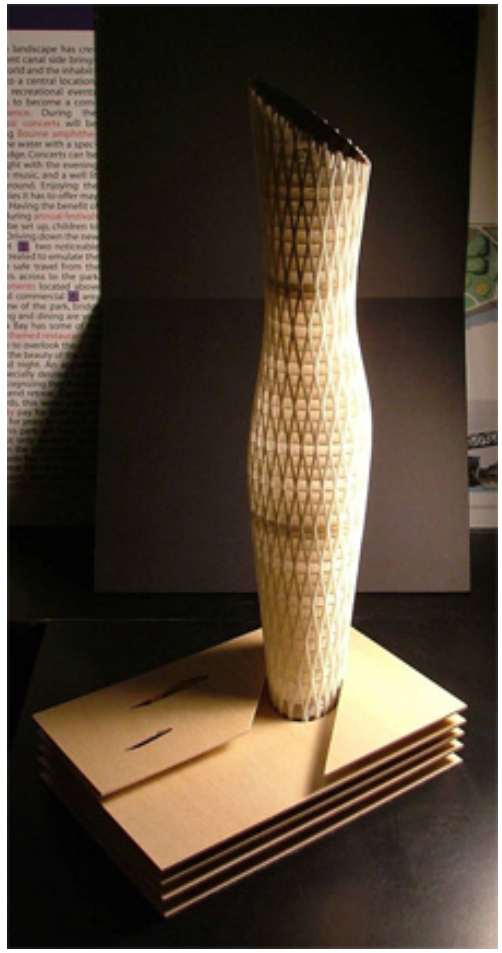

Figure 13: Skyscraper-Sway Tower. 
A site concept was generated as well and a physical model was milled using a "DaVinci" Techno Esel CNC router (see Figure 11).

The larger scale 3D printed model at 1:500 allowed representation of the skyscraper floor plates as well as the proposed primary "diamond braced" skin support matrix (see Figure 12).

The CADCAM generated parts were then assembled to convey the student's idea in physical form (see Figure 13).

\section{Conclusion}

Our pedagogy and research has shown the visualization and representational power of emerging 2D and 3D CADCAM tools. Architectural form concepts, heretofore, impossible to model and represent, much less manufacture and construct, are now possible due to CADCAM. Emerging designers are integrating "digital thinking" in their fundamental conceptualization of form. These creative free forms are only feasible for translation to tectonic form using digital design-make techniques. CADCAM tools are empowering designers for form exploration and design creativity. Current computing technology is now infusing the creative design process; the computer is becoming a design "partner" with the designer and is changing form and architecture; thus, we are now seeing unprecedented design-make creativity in architecture.

\section{References}

[1] Hammer, Michael, Re-engineering Work: Don't Automate, Obliterate, Harvard Business School, 1994.

[2] Barrow, Larry R., Cybernetic Architecture; Process and Form, The Impact of Information Technology, dissertation, Harvard Design School, 2000.

[3] Schodeck, Daniel, Martian Bechthold, Kimo Griggs, Kenneth Martin Kao, Marco Steinberg, Digital Design and Manufacturing - Computer-AidedDesign-Computer-Aided-Manufacturing, John Wiley and Sons, 2005.

[4] Kolarevic, Branko, Architecture in the Digital Age: Design and Manufacturing, Spoon Press, 2003.

[5] Lindsey, Bruce, Digital Gehry: Material Resistance/ Digital Construction, Birkauser, 2001.

[6] Lynn, Greg, Animate Form, Princeton Architectural Press, p.13, 1999.

[7] SHoP Talk, Metropolis Magazine, 12 March, 2006, http://www.metropolismag.com/html/content 0501/shp/index.html,

[8] Gehry Partners, Gehry Talks; Architecture + Process, Universe Publishing, 1999.

[9] Frank Gerhy For the Rest of Us, Wired Magazine, Nov 2004 issue, http://www.wired.com/wired/archive/12.11/gehry.html.

[10] Kieran, Stephan, James Timberlake, Prefabricating Architecture, McGraw-Hill, 2004. 